\title{
CORRELATION BETWEEN SMARTPHONE SCREEN TIME AND REACTION TIME IN YOUNG ADULTS OF AGE 18-25 YEARS
}

\author{
Dr.Shruti Ashok Gada(PT) \\ Department of Physiotherapy \\ K. J. Somaiya College of PT, Mumbai, \\ Maharashtra, India.
}

\begin{abstract}
Due to ever increasing use of smartphones and increase dependency on it, it has been a topic of great interest among researchers to find out how mobile phones have an effect on human anatomy and human brains but there haven't been several studies regarding the same. And as reaction time is one amongst the tool to measure cognitive function in human beings. This study included males and females of age 18-25years within BMI 18.5$22.9 \mathrm{~kg} / \mathrm{m} 2$ and having two weekly average screen-time of more than 4 hours. These individuals were asked to perform Deary Liewald's test for Simple and Choice reaction time. The included 54 participants $(3$ males and 51 females) and data collected did not pass normality, hence Spearman's test was used to find the correlation. The correlation coefficient ( $r$ value) and $p$ value for the correlation between smartphone screen time and Simple reaction time is 0.070 and 0.61 and for Choice reaction time is $\mathbf{- 0 . 0 4 8}$ and 0.729 respectively. The study shows no significant correlation between the parameters screen time and reaction time (simple and choice reaction time) since p $>0.05$.
\end{abstract}

Keywords - Smartphone use, reaction time, screen time, young adults.

\section{INTRODUCTION}

Smartphone has become an important a part of our existence. The recent development of the multifunctional smartphone and its resulting world popularity has modified the communication and data landscape; re-molded the interests, values, and needs of the many users; and triggered issues round the world regarding overuse and addiction. Smartphone has permanent access to the net and consequently all of the Internet's appealing and problematic content. Smartphones give varied gratifications, like sociableness, diversion, data finding, time management, coping methods, and social identity maintenance.[1]. Therefore, currently on a daily basis smartphone use has been increasing day by day by individuals of all age groups for his or her varied wants. India has $1,026.37$ million active mobile users on $2 \mathrm{G}, 3 \mathrm{G}$, and $4 \mathrm{G}$ networks-in 2018, TRAI (Telecom regulatory authority of

\author{
Dr.Nisha Dhasal(PT) \\ Department of Physiotherapy \\ K. J. Somaiya College of PT, Mumbai, \\ Maharashtra, India.
}

INDIA) aforesaid in its medium reports.[2]. The 2017 global Mobile consumer Survey explicit that the most use of mobile phone was within the people of age 18-24 years [3]. Specially during this pandemic with the obligatory lockdown, and work from home has inspired individuals to turn to their smartphones to remain connected.[4]. Hence the necessity and phone use has multiplied for various reasons. However, with tremendous advantages there are invariably some drawbacks. Moderate use of anything is nice however overuse has its own ill-effects. equally overuse of mobile phone has its own illeffects on the body. Overuse of smartphone is increasing, resulting in a great deal of physical and psychological effects.[5] As studies have showed that it has negative impact on health and it increases the chance of stress, depression, anxiety and additionally causes sleep disorder, restlessness and increased fatigue rates.it results in additional reduction in physical activity leading more towards an inactive life [6,7]. Reaction time(RT) is that the time interval between the applying of a stimulation and also the appearance of acceptable voluntary response by a subject i.e. it's the activity of however long it takes for brain and nerves to react to a stimulation. [ 8] it is typically expressed in milliseconds. reaction time is incredibly necessary for our everyday lives and it needs an intact sensory system, cognitive processing unit, and motor performance. It reflects the speed of the flow of neuronal and physiological, cognitive, and information processes which are created by the action of stimulation on the person's sensory system. The receipt of information (visual or auditory), its process, decision making, and giving the response or execution of the motor act are the processes that follow each other and build what we tend to call the time interval [9-11]. The RT involves the subsequent three stages: a) process of the external stimulus b) Its higher cognitive processing and decision-making c) Formulating a response. The Visual reaction time Pathway is as follows: 


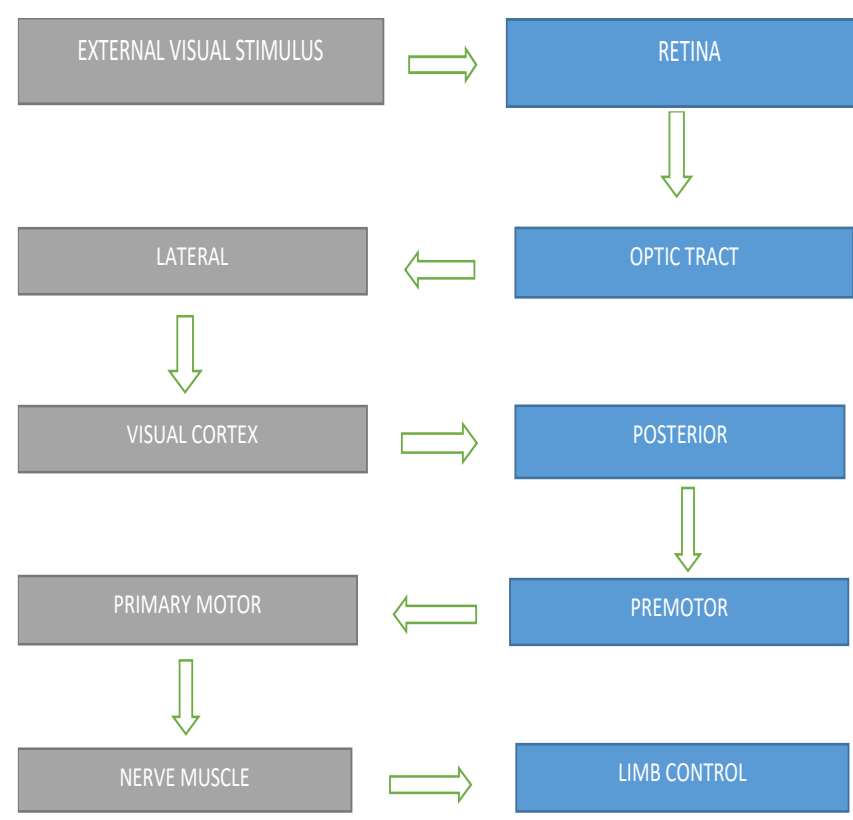

Fig.1.Visual reaction time pathway

There are three differing kinds of reaction time experiments, simple, recognition, and choice reaction time experiments. In simple reaction time experiments, there's just one stimulus and one response. In recognition reaction time experiments, there are some stimuli (the "memory set") that ought to be responded to and others (the "distracter set") that ought to not be responded to. In choice reaction time experiments, there are multiple stimuli and multiple responses and subject should provide a response that corresponds to the stimulation [12]. Thus, RT includes the time interval of: a) The sensory neural code latency traversing each in central and peripheral pathways b) each cognitive and Perceptive processes c) A motor signal traversing each peripheral and central neural structures d) And eventually the latency within the end effectors activation like muscle activation [9]. It involves stimulation stimulus, higher cognitive processing and decision making \& response programming information processing in humans are often measured with the assistance of RT that represents the concentration \& co-ordination skills of the person. The speed of this information processing may be assessed by using one stimulus (Simple RT) or multiple stimuli (Choice RT). [13,14] Many factors are shown to have an effect on reaction time together with gender, age, physical fitness, level of fatigue, distraction, alcohol, personality type, limb used for test, biological rhythm, and health and whether or not a visual or an auditory stimulus is given to test the reaction time[11]. reaction time is not dependent on socialcultural influences. Prolonged reaction time denotes attenuated performance [15].

With the appearance of technology therefore increasing mobile phone use it has been a topic of great interest among researchers to find out how mobile phones have an effect on human anatomy and human brains but there haven't been several studies regarding the same. A study done by Ju Hwan Kim et al titled as "Possible effect of radiofrequency magnetic field exposure on central nervous system" has found that Radiofrequency-EMF can induce changes in central nervous system nerve cells, together with neural cell apoptosis, changes within the function of the nerve myelin and ion channels; moreover, RF-EMF act as a stress source in living creatures. although these are animal-based studies and there is inadequate information on biological hazards to provide to produce answer to potential health risks.[16]
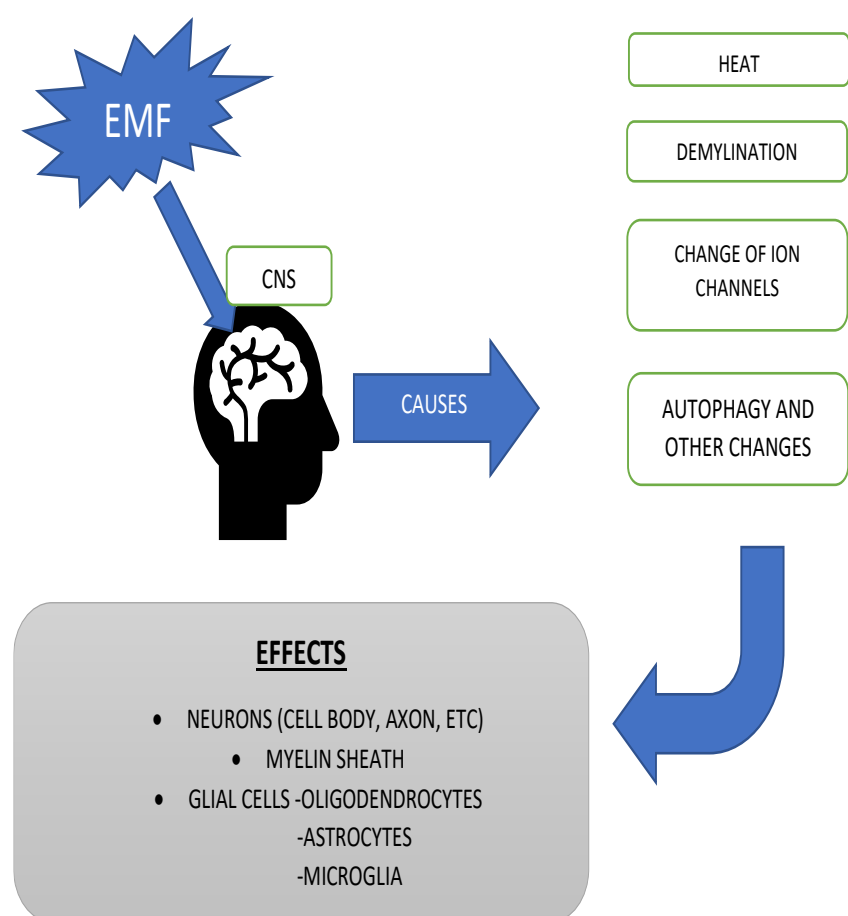

Fig.2.Possible effects of Electromagnetic field on the Central nervous system.

In addition to the present, several studies done by different researchers have shown some positive or negative impact of smartphone or its radiation on human system. Such studies are as follows:

Studies done on effect of smartphone use on peripheral nerves suggests that there's increase in latency and reduce in sensory nerve conduction velocity.[17] As we all know the visual and auditory effects of smartphone like there are studies speculating that mobile phone use might increase the cell death of retinal cells and additionally will increase the danger of acquiring hearing disorder, ear ache, blurred vision, ocular fatigue, headaches. [18,19] Also the effect of electromagnetic wave (EMR) emitted from MP have been demonstrated on cognitive function, immune system, circulatory system, genital system and also the endocrine system. MP conversation 


\section{International Journal of Engineering Applied Sciences and Technology, 2021 \\ Vol. 6, Issue 4, ISSN No. 2455-2143, Pages 276-284 \\ Published Online August 2021 in IJEAST (http://www.ijeast.com)}

decreases the ability to concentrate and impairs the eye necessary to perform complicated activities, affects visual evoked potential and graphical record (EEG) [20-25]. Since there's tremendous electrical activity in neural processes, the nervous system has been thought to be most sensitive to EMR. Recently it is reported that low dose of microwave radiation affects stress proteins and neural cells in brain. Processing and transmission of information in nervous system is based on bioelectromagnetic phenomena but effect of Electromagnetic radiation on peripheral nerves and peripheral nervous system is incredibly scanty and there's controversy in few reports that are available.

Similarly, studies related to affection of cognition due to mobile phone use has shown positive results with decline in memory and attention and learning impairment but the few studies done on reaction time have debatable results. [26-32]

As 'Reaction Time' is required in daily activities such as driving and while engaging in sports activities, in emergency situations, and in many day-to-day activities. Reaction time depends on nerve connectivity and signal pathways. Reaction time is important for individuals in all age group, any profession and also just to carry out activities of daily living. Impaired reaction time affects the individual's ability to respond quickly to specific stimulus which will also affect our ability to function and perform various ADL's. As also a study conducted by Lene H.Jacobson et al, analyzed. Reaction time is validated as a tool to measure cognitive function and quality of life in healthy individuals as well as patients. The results of this study suggested that simple reaction time test is related to cognitive function in healthy subjects and patients as measured by EKHO system (Simple Auditory Continuous Reaction Time Test) and Test Battery for Attentional Performance (Simple and Complex Visual Reaction Time Tests). Therefore, it's necessary to review the impact of smartphone use on reaction time as reaction time is one amongst the tool to measure cognitive function in human beings.[33]

Many studies have shown affection of smartphone use to central nervous system and peripheral nervous system and reaction time being an important tool to all individuals of all profession specially with the increase use in the youth it is important to find a correlation between the two. Hence it is important to study the effect of smart phone on reaction time in smartphone users.

Since there is inadequate information on effect of smartphone on human nervous system and with its increasing use and ill effects, so the aim of this study is to find a correlation between the smartphone use and reaction time. The objective of this study is to calculate Simple reaction time and Choice reaction time using Deary Liewald reaction time test and to find a correlation between the two variables.

\section{EXPERIMENT AND RESULTS}

\section{A.METHODOLOGY AND MATERIALS USED:}

This study is an observational analytical cross-sectional study which was conducted in K.J. Somaiya College of Physiotherapy over a duration of 6 months. The study population included healthy young individuals of aged 18-25 years (males and females).

A total number of 54 participants (both males and females) who fulfilled the inclusion criteria were included in this this study. Out of these participants 51 were females and 3 were males. The inclusion criteria being individuals (both males and females) within age group of 18-25 years of BMI within 18.5$22.9 \mathrm{~kg} / \mathrm{m} 2$ and with two weekly average screen time more than 4 hours.

The exclusion criteria being males and females of age group less than 18 and more than 25 years and of BMI less than 18.5 and more than $22.9 \mathrm{Kg} / \mathrm{m} 2$, visual impairments like blindness, recent fractures of hand or unhealed fracture, cognitively impaired conditions like MR, CP etc or

any neurological condition or musculoskeletal injury affecting body movement to perform the test and also participants with history of any chronic illness like diabetes mellitus, hypertension, neuromuscular disorders, psychiatric disorders, addictions to smoking, alcohol or tobacco are excluded from this study.

The outcome measure used in this study is Deary Liewald Simple and Choice Reaction Time Test [34]:

1) Simple Reaction Time test $-\alpha=0.94$

2) Choice Reaction Time test $-\alpha=0.97$

The materials used in this study are: Laptop, Visual Reaction Time tests [Deary Liewald Simple Reaction Time Test, Deary Liewald Choice Reaction Time Test], Table - to place the laptop, Chair - for the subject to sit, Measuring tape to measure height,Weighing Machine, Screenshots of two weekly report of smartphone use up till the day the reaction time test are done.

\section{B. STUDY PROCEDURE:}

1.To calculate Body Mass Index (BMI):

Body Mass Index $(\mathrm{kgs} / \mathrm{m} 2)=$ Weight $(\mathrm{kg}) /($ Height $) 2(\mathrm{~m}) 2$

Weight (in kilograms) was measured using digital weighing machine and height (in centimetres) was measured using a measuring tape.

BMI Criteria for Asian Adults (as per WHO) [35]:

Underweight $<18.5 \mathrm{~kg} / \mathrm{m} 2$

Normal Range $18.5-22.9 \mathrm{~kg} / \mathrm{m} 2$

Overweight $\geq 23 \mathrm{~kg} / \mathrm{m} 2$

So that only individual with normal BMI are selected.

2.To calculate the average smartphone screen time:

Smartphone screen time is the amount of time spent on the smartphone. For this study average of day-to-day screen time 


\section{International Journal of Engineering Applied Sciences and Technology, 2021 \\ Vol. 6, Issue 4, ISSN No. 2455-2143, Pages 276-284 \\ Published Online August 2021 in IJEAST (http://www.ijeast.com)}

of an individual for the last 2 weeks till the time of the reaction time test done are taken. It's calculated in hours.

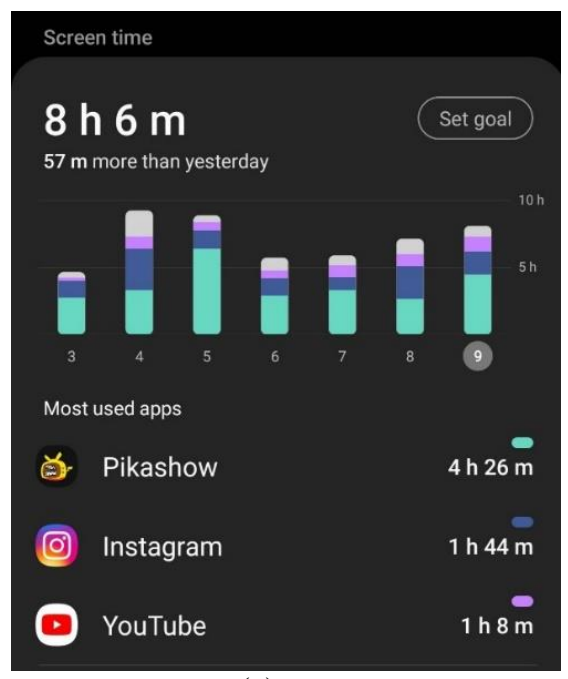

(a)

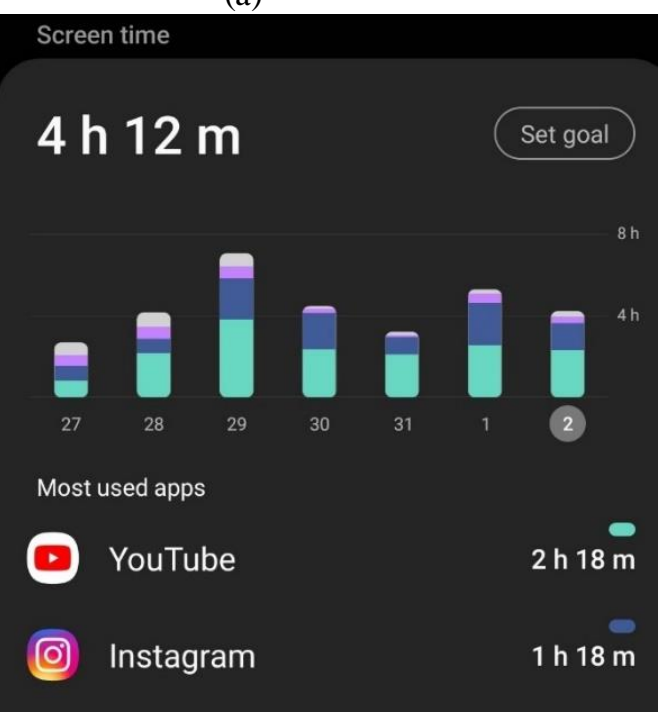

(b)

Fig.3. (a) and (b)Pictures showing an individual's two consecutive week's daily smartphone use time.

3.To calculate Deary Liewald Simple and Choice Reaction Time Test:

Simple Reaction Time Test: One white square was positioned approximately in the center of a computer screen, set against a blue background. The stimulus to respond was the appearance of a diagonal cross within the square. Each time a cross appeared, the participant had to respond by pressing the space bar key as quickly as possible. The cross remained on the laptop screen until the participant presses the key, after which it gets disappeared and another cross appeared shortly after.
Choice reaction time Test: Four white squares were

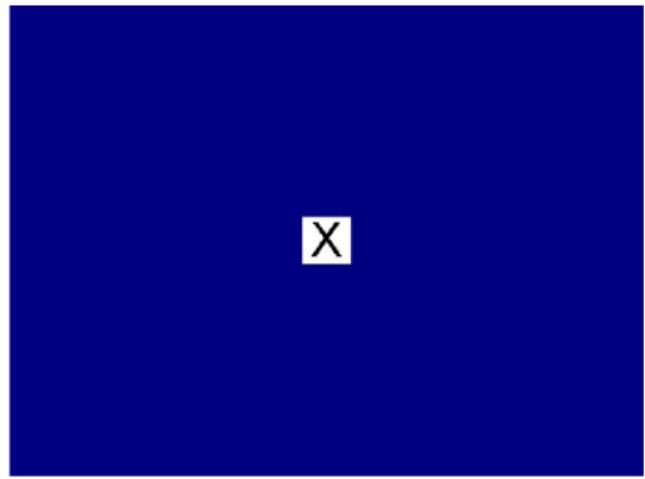

(a)

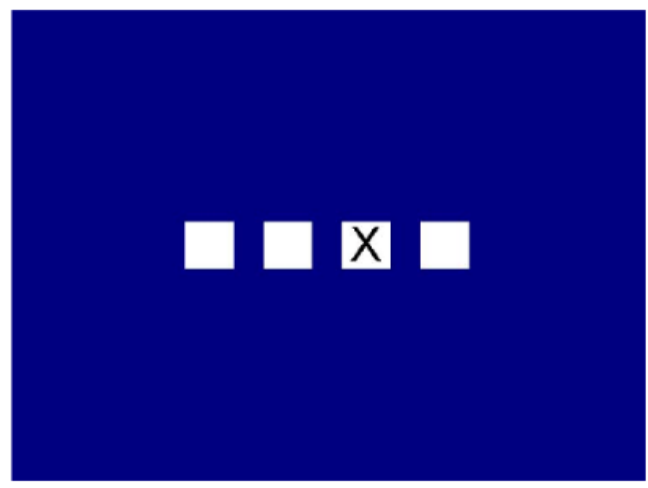

(b)

Ilustration of RTT: (a) SRT and (b) CRT.

Fig 4. Representation of Simple and Choice reaction time.

positioned in a very horizontal line across the center of laptop screen, set against a blue background. Four keys on a regular pc or portable computer keyboard corresponded to the various squares i.e. the position of the ' $z$ ' key corresponded to the box on the left, the ' $x$ ' key to the box second from the left, the 'comma' key to the box second from the right and therefore the 'full-stop' key to the box on the far right. The stimulant to reply was the appearance of a diagonal cross at intervals one amongst the squares. Participants were instructed to carefully rest the index and middle fingers of their left hand on the ' $z$ ' and therefore the ' $x$ ' keys, and therefore the index and middle fingers of their right hand on the 'comma' and 'full stop' keys respectively. A cross appeared randomly in one amongst the squares and participants had to reply as quickly as possible by pressing the corresponding key on the keyboard. every cross remained on the screen till one amongst the four keys was pressed, once that it disappeared and another cross appeared shortly after.

\section{C.RESULT}


International Journal of Engineering Applied Sciences and Technology, 2021

Vol. 6, Issue 4, ISSN No. 2455-2143, Pages 276-284

Published Online August 2021 in IJEAST (http://www.ijeast.com)

DEMOGRAPHIC DETAILS: Table 1

\begin{tabular}{|c|c|c|}
\hline \multicolumn{2}{|l|}{ MALE: FEMALE } & $1: 17$ \\
\hline MEAN AGE & & \\
\hline \multirow[t]{2}{*}{ MEAN BMI } & & 21.144 \\
\hline & MEAN & $\begin{array}{l}\text { STANDARD } \\
\text { DEVIATION }\end{array}$ \\
\hline $\begin{array}{l}\text { AVERAGE } \\
\text { SMARTPHONE } \\
\text { SCREEN TIME } \\
\text { (In hours) }\end{array}$ & 6.98 & 0.306 \\
\hline $\begin{array}{l}\text { SIMPLE } \\
\text { REACTION } \\
\text { TIME (msec) }\end{array}$ & 325.08 & 8.356 \\
\hline $\begin{array}{l}\text { CHOICE } \\
\text { REACTION } \\
\text { TIME (msec) }\end{array}$ & 510.57 & 10.053 \\
\hline
\end{tabular}

1.CORRELATION BETWEEN SMARTPHONE SCREEN TIME AND SIMPLE REACTION TIME IN YOUNG ADULTS OF AGE 18-25 YEARS.

Table 2: result for simple reaction time

\begin{tabular}{|l|l|}
\hline \multicolumn{2}{|l|}{ SIMPLE REACTION TIME $(\mathrm{msec})$} \\
\hline MEAN & 325.08 \\
\hline $\begin{array}{l}\text { STANDARD } \\
\text { DEVIATION }\end{array}$ & 8.356 \\
\hline $\begin{array}{l}\text { PASSED } \\
\text { NORMALITY }\end{array}$ & NO \\
\hline $\begin{array}{l}\text { CORRELATION } \\
\text { COEFFICIENT }(\mathrm{r} \\
\text { value) }\end{array}$ & 0.070 \\
\hline $\begin{array}{l}\text { STATISTICAL } \\
\text { TEST }\end{array}$ & $\begin{array}{l}\text { SPEARMAN'S } \\
\text { TEST }\end{array}$ \\
\hline P value & 0.613 \\
\hline SIGNIFICANE & $\begin{array}{l}\text { NOT } \\
\text { SIGNIFICANT }\end{array}$ \\
\hline
\end{tabular}

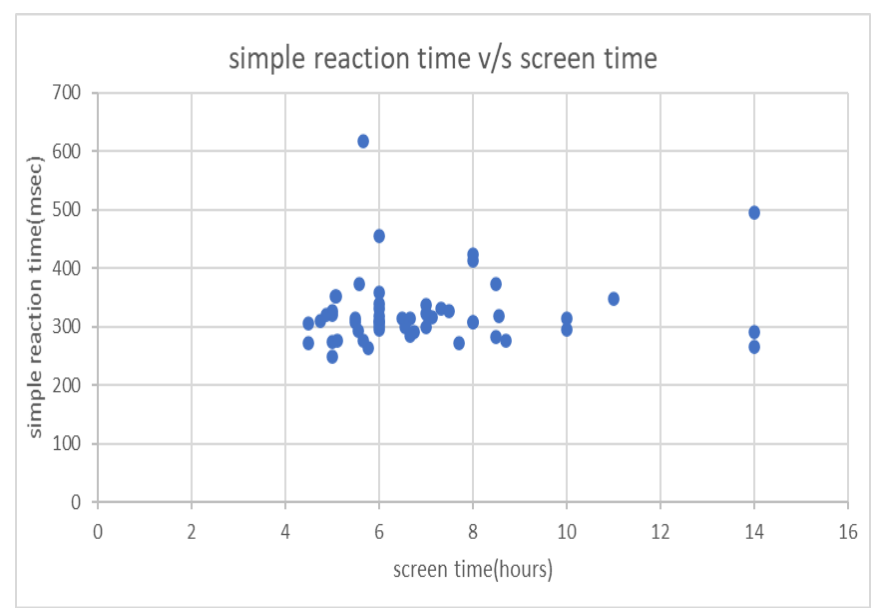

FIG5: Graphical representation of correlation between smartphone screen time and simple reaction time.

INFERENCE: There is no significant correlation between smartphone screen time and simple reaction time.

2. CORRELATION BETWEEN SMARTPHONE SCREEN TIME AND CHOICEREACTION TIME IN YOUNG ADULTS OF AGE 18-25 YEARS.

Table 3: result for choice reaction time

\begin{tabular}{|l|l|}
\hline \multicolumn{2}{|l|}{ CHOICE REACTION TIME (msec) } \\
\hline MEAN & 510.8 \\
\hline $\begin{array}{l}\text { STANDARD } \\
\text { DEVIATION }\end{array}$ & 10.05 \\
\hline $\begin{array}{l}\text { PASSED } \\
\text { NORMALITY }\end{array}$ & NO \\
\hline $\begin{array}{l}\text { CORRELATION } \\
\text { COEFFICIENT ( } \\
\text { value) }\end{array}$ & -0.048 \\
\hline $\begin{array}{l}\text { STATISTICAL } \\
\text { TEST }\end{array}$ & $\begin{array}{l}\text { SPEARMAN'S } \\
\text { TEST }\end{array}$ \\
\hline P value & 0.729 \\
\hline SIGNIFICANE & $\begin{array}{l}\text { NOT } \\
\text { SIGNIFICANT }\end{array}$ \\
\hline
\end{tabular}




\section{International Journal of Engineering Applied Sciences and Technology, 2021 \\ Vol. 6, Issue 4, ISSN No. 2455-2143, Pages 276-284 \\ Published Online August 2021 in IJEAST (http://www.ijeast.com)}

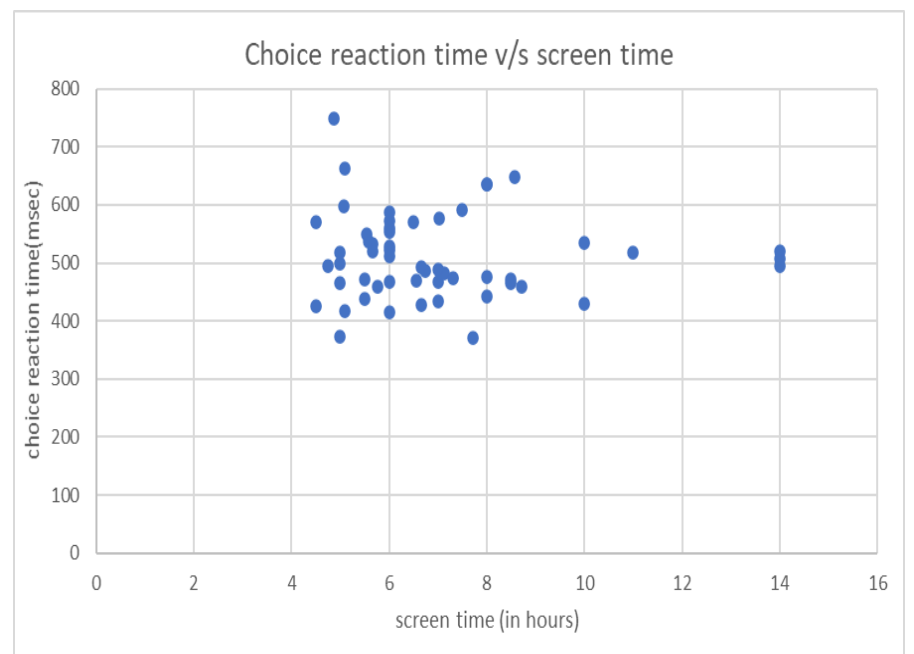

FIG6: Graphical representation of correlation between smartphone screen time and simple reaction time.

INFERENCE: There is no significant correlation between smartphone screen time and choice reaction time.

\section{D.DISCUSSION}

This study was aimed to find a correlation between smartphone screen time and reaction time in individual of age 18-25 years old. This study includes young individuals both male and female of age of 18-25 years with their two weekly average screen time(in hours) $>4$ hours and all within normal BMI range to perform the Dieary Liewald test for Simple Reaction Time(SRT) and Choice Reaction Time(CRT) which is measured in milliseconds. The result of this study showed no significant correlation between smartphone screen time and simple reaction time and also between smartphone screen time and choice reaction time which can be due to any of the following reason: 1-According to author Mark Dombeck, Ph.D. (clinical psychology) in his study titled "Cell phone radiation slows reaction time and improves memory" It appears that the radiation from cell phones really exerts a little however real short impact on brain activity, reducing the brain's general reaction time abilities. In effect, talking on the mobile phone seems to alter your brain, enabling you to respond slower than traditional. Following well established laboratory procedure, Dr. Con Stough, director of the Brain Sciences Institute at Swinburne University of Technology in Melbourne, and his colleagues divided study participants into experimental and control groups, and so exposed the experimental population to cell-phone equivalent amounts of electromagnetic wave (e.g., radio waves). The control population got treated equally, except they didn't receive any actual radiation. once exposed to the radiation each teams of participants sat for neuropsychological examinations that measured their brain functioning through indirect measurements of mental performance: memory, attention, reaction time, etc. statistical examination of the neuropsychological information disclosed that the radiationexposed population showed a small impairment in terms of reaction time responding, and also, a small memory benefit. Hence, the study concludes that the smartphone radiation have a short term impact on the systema nervosum that is tough to find during a onetime study, so a longitudinal study ought to be done to grasp its impact over the time.[49] 2-There is a vast misconception round the population that smartphone overuse is equivalent to smartphone addiction that isn't true. there is difference in both. Problematic smartphone use is termed by some researchers to be a type of psychological or behavioural dependence on cell phones, closely associated with other varieties of digital media overuse like social media addiction or internet addiction disorder whereby overuse is simply one of the factors used to outline such individuals. Hence a study done in geriatric population has shown reduced RT in smartphone addicted because the brain activity within the somatosensory cortex was stronger once smartphone users did tons of typing and swiping, and that signal strength depended on however recently such digital activity occurred. The researchers found that the a lot of the volunteers had used their smartphone within the days before the electroencephalogram recording session, the more intense their brain responses to tactile stimulation of the thumb.[41]

Also a study titled 'Effects of electromagnetic radiation of mobile phones on the central nervous system' by author K.A. Hossmann and D.M. Hermann has expressed his concern about the potential interactions of electromagnetic wave with the human organism and, specifically, the brain. The effects on neural electrical activity, energy metabolism, genomic responses, neurochemical balance, blood-brain barrier permeability, cognitive function, sleep, and varied brain diseases including brain tumours were reviewed. Most of the according effects are small as long because the radiation intensity remains within the nonthermal range, and none of the analysis reviewed offers an indication of the mechanisms concerned at this range. The article also states that different researchers have witnessed interaction between electromagnetic fields with cognitive functions. the most finding was a shortening of reaction times once exposure to ELF or GSM microwave fields, significantly during tasks that need attention or manipulation of information within the memory. [38]Similar to this study several researchers like Ju Hwan Kim et al and plenty of others have studied upon the impact of electromagnetic wave on nervous system however with debatable results and inadequate info as most of them were animal-based research and not a lot of info on human studies is obtainable. At present, there's very little proof that periodical or continuous microwave exposure at power and frequencies related to mobile communication may interfere with the functional and structural integrity of the brain. Under experimental conditions, most of the positive results according thus far can be attributed to thermal effects. Such effects are 


\section{International Journal of Engineering Applied Sciences and Technology, 2021 \\ Vol. 6, Issue 4, ISSN No. 2455-2143, Pages 276-284 \\ Published Online August 2021 in IJEAST (http://www.ijeast.com)}

unlikely to occur throughout regular use of mobile telephones as a result of the entire emitted power is much too low to increase whole body temperature, and also because local elevation of brain temperature if at all present, would be prevented by the thermostabilizing effect of the circulating blood. Negative knowledge doesn't exclude the chance of minor microwave elicited biological effects on the brain, however the smaller these side effects are, the less is their contribution to the combined health risk alternative environmental influences could confer to the brain. And additionally alternative pertubations ascertained beneath such experimental conditions can be associated with procedural side effects like immobilization stress, that un-anesthetized animals could suffer after they are placed in restrictive animal holders. Experimental setups should, therefore, be designed with care to copy the actual exposure conditions for human users of mobile communication systems.

\section{CONCLUSION}

The study aims to find correlation between screen time and reaction. The study shows no significant correlation between the parameters screen time and reaction time (simple and choice reaction time).

\section{LIMITATION:}

- The study is limited to young adults and is not a longterm study to explore the relationship between the variables with prolonged use of phone over time.

- The study does not include a smartphone addiction of an individual which would also play a role in affecting their reaction time and to give a better result.

- It is a single center study.

\section{SUGGESTIONS:}

- To do a longitudinal study to study the long-term effects of smartphone usage on reaction time over time with prolonged overuse.

- To also take smartphone addiction into consideration.

- $\quad$ To conduct a multicentered study

\section{ACKNOWLEDGEMENT}

I, Shruti Gada, Intern(B.P.Th), batch 2016-17 would like to thank Dr. Shweta Manwadkar, Principal of K.J. Somaiya College of Physiotherapy and my guide Dr. Nisha Dhasal, Assistant lecturer for their sincere efforts and guidance throughout the duration of this study. Special thanks to my mentor Dr.Isha Tajane for always supporting me and helping me through this entire journey and also in my research. I also extend my sincere gratitude to all the study participants for their co-operation.

\section{REFERENCES}

1] Tayana Panova and Xavier Carbonell . Is smartphone addiction really an addiction? J Behav Addict. 2018 Jun; 7(2): 252-259.

2]Statistics of active mobile users in India,2018.www.trai.gov.in or www.telecomlead.com. 3] James A. Roberts, Luc Honore Petnji Yaya, Chris Manolis. The invisible addiction: Cell-phone activities and addiction among male and female college students. Journal of Behavioral Addictions. 2014;3(4):254-265.

4] Zubair Ahmed Ratan, Sojib Bin Zaman, Sheikh Mohammed Shariful Islam, and Hassan Hosseinzadeh . Smartphone overuse: a hidden crisis in Covid-19. Health Policy Technol. 2021 Mar; 10(1): 21-22. Published online 2021 Jan 23.

5] https://www.livemint.com/technology/apps/average-timespent-on-smartphone-up-25-to-6-9-hrs-amid-pandemic-report11607859712125.html

6] SeyyedSalmanAlavi , HamedAlaghemandan, Mohammadrez a Reza Maracy et al. Impact of Addiction to Internet on a Number of Psychiatric Symptoms in Students of Isfahan Universities, Iran, 2010. Int J Prev Med . 2012 Feb;3(2):122-7.

7] Sara Thomée -, Annika Härenstam, Mats Hagberg. Mobile Phone Use and Stress, Sleep Disturbances, and Symptoms of Depression Among Young Adults--A Prospective Cohort Study. BMC Public Health. 2011 Jan 31;11:66.

8] Lalita H. Nikam and Jayshree V. Gadkari. Effect of age, gender and body mass index on visual and auditory reaction times in Indian population, Indian Journal of Physiology and Pharmacology, 2012, Volume 56 Number 1 Pages 94 .

9]M. Madan, D. P. Thombre, A. K. Das, N. Subramanian, and S. Chandrasekar, "Reaction time in clinical diabetes mellitus," Indian Journal of Physiology and Pharmacology, vol. 28, no. 4, pp. 311-314, 1984.

10]A. Malathi, V. G. Parulkar, H. S. Dhavale, and C. Pinto, "A preliminary study of reaction time in schizophrenics," Indian Journal of Physiology and Pharmacology, vol. 34, no. 1, pp. 54-56, 1990.

11]H. Baayen and P. Milin, "Analyzing reaction times," International Journal of Psychological Research, vol. 3, no. 2, pp. 1-27, 2010. 


\section{International Journal of Engineering Applied Sciences and Technology, 2021 \\ Vol. 6, Issue 4, ISSN No. 2455-2143, Pages 276-284 \\ Published Online August 2021 in IJEAST (http://www.ijeast.com)}

12]J. O. Miller and K. Low, "Motor processes in simple, go/no-go, and choice reaction time tasks: a psychophysiological analysis," Journal of Experimental Psychology: Human Perception and Performance, vol. 27, no. 2, pp. 266-289, 2001.

13] Asmita S. Nene, Pushpa A. Pazare and Karun D. Sharma. A study of relation between Body Mass Index and Simple Reaction Time in healthy young females, Indian Journal of Physiology and Pharmacology, 2011, Volume 55 Number 3 Pages 288- 291.

14] Samad Esmaeilzadeh, Reza Farzizadeh, Hassan-Ali Kalantari et al. Is obesity associated with impaired reaction time in youth?, Springer Nature Switzerland AG 2018, 16 November 2018.

15] C. Shah, P. A. Gokhale, and H. B. Mehta, "Effect of mobile use on reaction time," Al Ameen Journal of Medical Science, vol. 3, no. 2, pp. 160-164, 2010.

16] Ju Hwan Kim, Jin-Koo Lee, Hyung-Gun Kim, Kyu-Bong Kim, and Hak Rim Kim. Possible effect of radiofrequencyelectromagnetic field exposure on central nervous system. Biomol Ther (Seoul). 2019 May; 27(3): 265-275.Published online 2018 Nov 27

17]K. Singhand K. Dabla. Effect of Electromagnetic Waves Emitted from Mobile Phone on Nerve Conduction Velocity in Ulnar Nerve in Adult Males .IJARESM. Volume 3, Issue 1; January-March, 2016, pp. 13-17

18] K. Dabla, K. Singh. Effect of Electromagnetic Waves Emitted from Mobile Phone on Nerve Conduction Velocity of Median Nerve in Adult Males.IJARESM. Volume 4, Issue 12, December- 2016 23-27.

19] Lene H. Jakobsen, Janice M. Sorensen, Ingeborg K. Rask et al. Validation of reaction time as a measure of cognitive function and quality of life in healthy subjects and patients. Volume 27 Issue 5 Pages 561-570, May 2011.

20] Yost MG, Liburdy RP. Time-varying and static magnetic fields act in combination to alter calcium signal transduction in the lymphocyte. Fed Eur Biochem Soc J.1992; 296:117-22.

21] Singh K, Dutta S. Effect of electromagnetic waves emitted from mobile phone on QT interval variables of ECG and rate pressure product (RPP). Indian J Physiol Pharmacol. 2011; $55: 167$

22] Kumar S, Nirala JP, Behari J, Paulraj R. Effect of electromagnetic irradiation produced by $3 \mathrm{G}$ mobile phone on male rat reproductive system in a simulated scenario. Indian $\mathbf{J}$ Exp Biol. 2014; 52(9):890-7.
23]. Sarookhani MR, Asiabanha Rezaei M, Safari A, Zaroushani V, Ziaeiha. The influence of $950 \mathrm{MHz}$ magnetic field (mobile phone radiation) on sex organ and adrenal functions of male rabbits. Afr J Biochem res. 2011; 5(2):65-8.

24]Hinrikus H, Tomson R, Lass J, Karal D, Kalda J, Tuulik V. Low-level microwave radiation effect on nerve pulse conduction velocity. Environmentalist. 2005; 25:157-63.

25]Christian Haarala et al. Effects of a $902 \mathrm{MHz}$ Mobile Phone on Cerebral Blood Flow in Humans: A PET Study. Neuroreport 2003 Nov 14;14(16):2019-23.

26] Seo-young Kang, Ji Eun Hong, EJ Choi, Jungmook Lyu. Blue-light induces the selective cell death of photoreceptors in mouse retina .J Korean Ophthalmic Opt Soc 21 (1), 69-76, 2016.

27] Yoon Soo Jang, Ungsoo Samuel Kim, Seung-Hee Baek, et al Research on ocular fatigability induced by multimedia and instrument features. Journal of the Korean Ophthalmological Society 53 (5), 689-693.

28]Sultan A Meo et al. Mobile Phone Related-Hazards and Subjective Hearing and Vision Symptoms in the Saudi Population. Int J Occup Med Environ Health. 2005. 18(1):537.

29]Dong Geon Lee, Chae Won Han, Hwak Yung Lee et al. Effects of a smart phone-based game on balance ability and dizziness in healthy adult individuals. Journal of Human Sport and Exercise, 14(4), 793-801.

30] Young-Hyun Park, Chang-Man An, and Sung-Jun Moon. Effects of visual fatigue caused by smartphones on balance function in healthy adults.J Phys Ther Sci. 2017 Feb; 29(2): 221-223.

31]Henrietta Nittby, Gustav Grafström, Dong Ping Tian et al. Cognitive impairment in rats after long-term exposure to GSM-900 mobile phone radiation. Bioelectromagnetics. Nov 2008. 29:219-232.

32] F Kalafatakis et al. Mobile Phone Use for 5 Minutes Can Cause Significant Memory Impairment in Humans.Hell J Nucl Med. Sep-Dec 2017;20 Suppl:146-154.

33]Lene H. Jakobsen M.Sc., Janice M. Sorensen M.Sc., Ingeborg K. Rask M.Sc. et al.Validation of reaction time as a measure of cognitive function and quality of life in healthy subjects and patients. Nutrition Journal: Volume 27 Issue 5 Pages 561-570, May 2011. 
34] Ian J. Deary, David Liewald and Jack Nissan. A free, easy-to-use, computerbased simple and four-choice reaction time programme: The Deary-Liewald reaction time task, Behavior Research Journal, 2011, Issue 43, Pages 258 - 268

35]International Obesity task force. The Asia Pacific Perspective : redefining obesity and it's treatment, Chapter 2 Assessment/Diagnosis, February 2000, Pages15-18.

36] Mark Donbeck. Phd. in clinical psychology https://www.mentalhelp.net/blogs/cell-phone-radiation-slowsreaction-time-improves-memory/

37] Simran Grewal and Rajneet Kaur Sahni.Effect of smartphone addiction on reaction time in geriatric population.J Nov Physiother Phys rehabilation.16 May,2019.6(1):005-009. 38]Hossmann KA, Hermann DM. Effects of electromagnetic radiation of mobile phones on the central nervous system. Bioelectromagnetics. 2003 Jan;24(1):49-62. doi: 10.1002/bem.10068. PMID: 12483665. 